- flagship programmes, which are designed to promote information and communication technologies through interdisciplinary research. The project is partnered by around 80 universities and research institutes and its work is organized into three broad interlocking sections: computing, neuroscience and medicine. The cognitive-neuroscience subproject addresses how the brain contributes to tasks such as generating and controlling emotion and making decisions.

The HBP's coordinator, neuroscientist Henry Markram of the Swiss Federal Institute of Technology in Lausanne (EPFL), says that the criticisms represent a minority view of HBP participants and that accusations of lack of transparency are "entirely groundless". "It would be difficult to be more transparent or responsive to our members than we are," he says. He declined to comment specifically on the letter.

Still, he agreed to implement recommendations made by the HBP's advisory boards last week in their bid to diffuse tensions. The boards say that the chair should be elected by the research board - currently the leaders of the 13 scientific subprojects - and should not be a subproject leader, to avoid conflict of interest. They also recommend that the research board elect the executive committee for terms limited to three years.

But some do not think that these measures are sufficient. Cognitive neuroscientist Zachary Mainen, director of the Champalimaud Neuroscience Programme in Lisbon, who helped to organize the protest letter says that they do not deal with a fundamental failing. The HBP should represent the views of all its members and the neuroscience community at large, he says - not just of the executive board.

The letter, signed by many leading researchinstitute directors, some of whom are not connected with the project, calls for the review process for the second phase to proceed in an open fashion and for the identity of the reviewers to be made public. It also wants representatives of the reviewing panel on the external steering committee for the period of the funding under review to ensure that the panel's recommendations are put into effect.

\section{BOYCOTT THREAT}

The 154 signatories say that if their requests cannot be implemented, the European Commission should reallocate the project's funding - perhaps to the European Research Council, Europe's basic-research funding agency, for broad neuroscience-directed investigator-driven grants. The commission provides only half of the HBP's $€ 100$-million (US\$136-million) annual budget; the rest must come from the member states of the European Union through competitive grants. The signatories pledge not to apply for such funds unless their concerns are addressed.

Preparations for the next round of funding began in January, and the rift between neuroscientists immediately became apparent. Dehaene, for instance, says that he was "dismayed at the unprecedented level of bureaucracy, gobbledegook and absence of transparent democratic reviewing" in the HBP's governance. "There was no need to rewrite the project only months after it came into existence," he says.

The tensions seem to be confined to the neuroscience section of the programme. Physicist Karlheinz Meier of Germany's Heidelberg University, who heads the HBP's computing and robotic section - as well as its futuristic computing platform - says that his section is happy. "I don't see any difference in openness and transparency than in any other mega-project as it approaches a transition stage," he says. "Maybe biologists are less used to projects of this scale than physicists are."

Thomas Skordas, who heads the European Commission's flagships programme, says that the commission closely monitors the progress of the projects and has the power to intervene if it deems it necessary. In a few months, he says, the commission will publish a policy document that will clarify in detail its expectations regarding governance. - SEE EDITORIAL, PAGE 125.

\section{BY T V PADMA}

$\mathrm{I}$ ndia's new government certainly seems to be cracking on with its job. Within two weeks of taking office, environment minister Prakash Javadekar had rolled out an online system to speed up approvals for development projects that might have environmental impacts. And a system for clearing permits for projects in forests is hot on its heels. But ecologists are concerned that the speed will do nothing to improve an already poor-quality system, and may, in fact, make things worse.

Javadekar had inherited a backlog of hundreds of cases (see 'Projects in waiting') and pledged to wipe clean the ministry's image as a hurdle to development. But although those

\section{PROJECTS IN WAITING}

India's new environment minister is crunching through the backlog of development-project applications, but still has several hundred left to process.

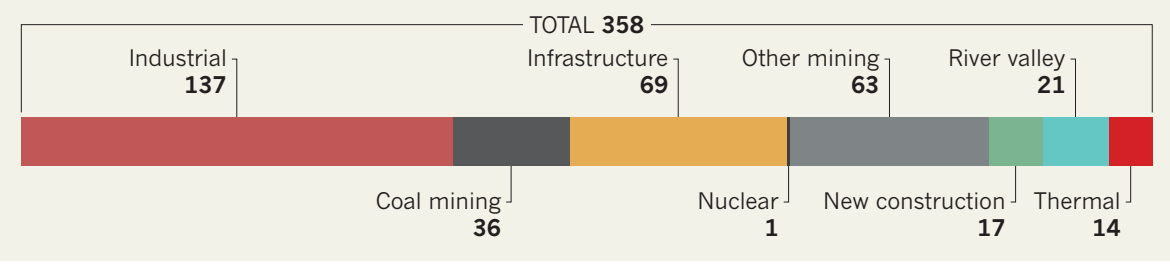

fed up with India's notorious red tape welcome the move, others worry that the environment may suffer.

People applying for development projects such as roads, mines or dams are first told by the ministry what type of environmental-impact assessment (EIA) they need. (For example, if a planned development is in an area where threatened species live, then a wildlife assessment may be needed.) Then - in a step that predates Javadekar's appointment and that several environmental scientists vehemently oppose 


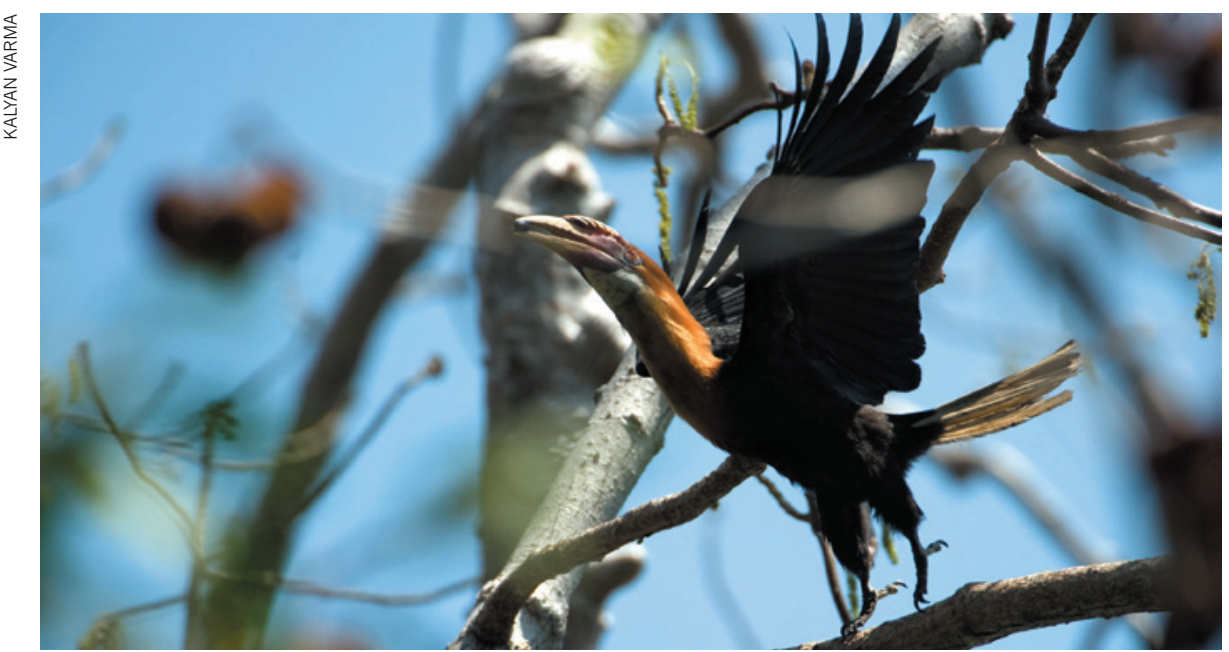

The Narcondam hornbill (Aceros narcondami) is found only on Narcondam Island in the Bay of Bengal.

— companies can choose who will do their EIAs.

The ministry says that it will turn around applications that contain the correct, completed EIA in 60 days, and will face a penalty for any delays it does not explain. The previous turnaround was 105 days, but it was not strictly enforced.

Javadekar has also promised that applications that get no objections from the ministry, environmental groups or local residents within two months will automatically be approved. Holding up clearances, he says, "amounts to not making a decision or action".

The changes have worried ecologists and wildlife experts. "There is no problem setting deadlines," says Rahul Kaul, senior director of the Wildlife Trust of India near New Delhi. "If the purpose of online clearances is to bring in transparency in the clearance system, it should be welcome - but I am quite sceptical that the whole review process can be accomplished in two months."

Javadekar's pledge for speedier clearances coincides with a series of articles in India's daily newspapers on an Intelligence Bureau report that accused specific non-governmental organizations (NGOs), activists and members of the media of blocking the country's development, and said that NGO campaigns had contributed to a $2-3 \%$ decline in India's gross domestic product.

Javadekar is prioritizing defence projects and infrastructure applications that involve India's border with China. He has, for instance,

approved the second phase of a defence project known as 'Project Seabird' to build a naval base in Karwar, on India's west coast, and a project that was rejected by the previous government to build a radar station on Narcondam Island to monitor the strong Chinese presence on the nearby Coco Islands.

Narcondam Island, part of the Andaman and Nicobar chain in the Bay of Bengal, is on the United Nations Educational, Scientific and Cultural Organization's 'tentative' list - places that nations consider worthy of listing as a world heritage site. It is described as "an outstanding example of ongoing ecological and evolutionary processes" and has

\section{"Speedy clearances will magnify the flaws of an already flawed system."} geomorphic features that represent "major stages of earth's history", the listing says.

Narcondam is home to a number of species endemic to the island chain, including the world's only population of the endangered Narcondam hornbill (Aceros narcondami). Only around 350 individuals are thought to be left on the island, Kaul says, so "even small developments will have an impact".

The government's action does not address the real problems with the system, which include shoddy EIAs, says Kartik Shanker, a conservationist at the Indian Institute of Science's Centre for Ecological Sciences in Bangalore. If applicants appoint their own
EIA assessors, one can hardly expect them to be neutral, he says. "Speedy clearances will magnify the flaws of an already flawed system. We are all in favour of efficiency, but we do need to make consultative and considered decisions when they could have long-term consequences."

Prodipto Ghosh, former environment secretary and now a policy expert at the Energy and Resources Institute in New Delhi, says that sub-standard EIAs often need to be rectified, and that causes delays. The 500-page documents are complicated and are often prepared by consultants who have low technical skills and do a poor job of data collection, analysis and interpretation, he says. Data-recording instruments are often inaccurately calibrated and the data themselves are scattered and cannot be accessed at one place, he adds.

Ecologist Madhav Gadgil at Goa University in Taleigão cites a 2013 report on leases for mining projects in India's biodiversity hotspot, the Western Ghats. The two-year study carried out by the Centre for Environment Education, headquartered in Ahmedabad, looked at 105 mining operations in the state during the previous two years, and found that EIAs, compliance reports and environment management plans were all "highly deficient in information" relating to major environmental factors such as land-use patterns, water resources, biodiversity, air quality and the potential impact of air pollution on the health of local people.

In 2011, the Western Ghats Ecology Expert Panel, which Gadgil headed, recommended that the government undertake "a radical reform of the environmental clearance process by assigning EIAs to a neutral competent body that does not depend on payment by project proponents", Gadgil says. It also pushed for public hearings and mandatory involvement of biodiversity management committees. The report was, however, bypassed by another review commissioned by the same government (see Nature 504, 200; 2013).

Some environment scientists are also worried that the new government will overturn previous decisions to reject projects with environmental impacts. For example, it has said that it would review a ban imposed by the previous government on mining within one kilometre of wildlife sanctuaries in Goa.

India's environment ministry, Gadgil says, is "running in the wrong direction".
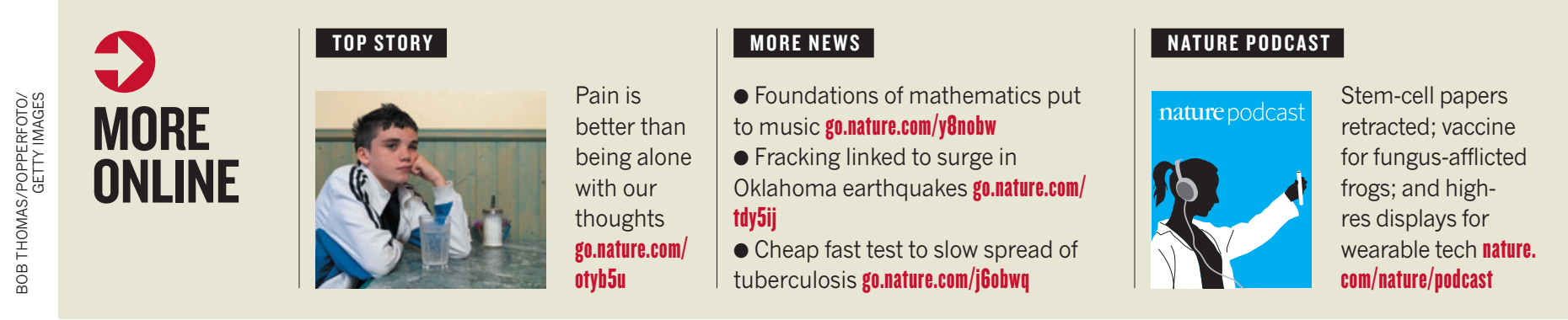